\title{
Utilização De Ferramentas Gerenciais Para O Controle De Estoques: Um Estudo De Caso De Uma Empresa Do Setor Alimentício
}

\section{Use Of Management Tools For Stock Control: A Case Study Of A Food Industry Company}

\author{
Diego Camilo Ferreira Sousa ${ }^{1}$, Calline Neves de Queiroz Claudino ${ }^{2}$, Joás Tomaz de Aquino ${ }^{1}$, Fagner José \\ Coutinho de Melo ${ }^{1}$
}

${ }^{1}$ Universidade Federal de Pernambuco, UFPE, Brasil. ${ }^{2}$ Universidade Federal da Paraíba, UFPB, Brasil.

Correspondência: Fagner José Coutinho de Melo. Cidade Universitária, CEP: 58051-900, João Pessoa, PB, Brasil. Fone: +55 (83) 3216-7200. E-mail: fagner_especial@yahoo.com.br.

Recebido: 02 de novembro de 2016 Aceito: 20 de dezembro de 2017 Publicado: 31 de maio de 2018

DOI: http://dx.doi.org/10.21714/1679-18272017v15n2.p546-563

\begin{abstract}
Resumo
A gestão de estoques tem se tornado um assunto muito importante tanto nos meios acadêmicos como na prática empresarial, pois seu planejamento e controle visam satisfazer às prioridades competitivas da organização, devido aos diversos custos envolvidos na sua decisão. Desta maneira este trabalho tem por objetivo analisar o atual sistema de gerenciamento de estoque de uma empresa do setor alimentício localizada em Pernambuco e propor melhorias a esse sistema, por meio do uso de ferramentas de análise e acompanhamento, que em muitas indústrias, os estoques, são elementos estratégicos para as operações da organização. Assim foi realizado um diagnóstico inicial e propostas melhorias em três eixos, a saber: (i) controle da programação FIFO para controlar os prazos de validade dos produtos, (ii) controle de estoque - classificação $\mathrm{ABC}$ do estoque, e (iii) a representação gráfica do layout. Assim, com a aplicação dessas técnicas de controle de estoque e fazendo uso de indicadores haverá melhorias para a gestão. Este trabalho pode ser considerado como aplicado e estudo de caso. Como resultado, foi possível perceber que, para uma melhor eficiência da operação do sistema de estoque da empresa, elementos como: gestão, treinamento, estrutura e controle dos estoques devem ser tratados de forma alinhada e interdependente, buscando balizar não só a capacidade interna da empresa, mas a cadeia produtiva na qual ela está inserida, ratificando as ideias difundidas pela literatura. $\mathrm{O}$ estudo contribui para literatura no que se refere ao gap teórico x prático a respeito do controle de estoque em organizações do setor alimentício.
\end{abstract}

Palavras-chave: Estoque; Demanda; Gestão de Estoque; Ferramentas de Controle.

\begin{abstract}
Stock management has become a very important issue in both academia and business practice because its planning and control aim to satisfy the competitive priorities of the organization due to the various costs involved in its decision. In this way the objective of this work is to analyze the current inventory management system of a food company located in Pernambuco and propose improvements to this system through the use of analysis and monitoring tools that in many industries, are strategic elements for the organization's operations. Thus, an initial diagnosis was made and improvements were proposed in three axes, namely: (i) control of FIFO scheduling to control the validity of products, (ii) stock control - ABC classification of inventory, and (iii) representation graphic layout. Thus, with the application of these inventory control techniques and making use of indicators there will be improvements to the management. This work can be considered as applied and case study. As a result, it was possible to perceive that, for a better efficiency of the operation of the company's stock system, elements such as: management, training, structure and inventory control should be treated in an aligned and interdependent way, aiming at company, but the productive chain in which it is inserted, ratifying the ideas disseminated in the literature. The study contributes to the literature regarding the theoretical and practical gap regarding stock control in food sector organizations.
\end{abstract}

Keywords: Stock;

Demand; Stock Management; Control tools. 


\section{Introdução}

As organizações buscam atender as mudanças nas tendências de consumo, ofertando um crescente número de produtos e sendo obrigada a ter alta capacidade produtiva para o atendimento adequado à demanda. No entanto, para manter-se competitiva a empresa investe em ciclos de produção com menor volume de produtos, a fim de se adequar aos curtos prazos de validade e atender melhor às diferentes especificações ou "mix de produtos" (MELO; AQUINO, 2015; CHIARINI; VAGNONI, 2017; SANTOS et al., 2017; SANTOS et al., 2017), visando sempre a redução da lacuna entre oferta e demanda.

Nesse sentido, o presente trabalho analisou uma empresa que atua no segmento de produção de bens alimentícios. A análise da empresa estudo de caso possui importância devido a ampliação no seu mix de produtos, há cinco anos a empresa possuía capacidade e infraestrutura produtiva para elaboração de 83 produtos e atualmente ela fabrica mais de 130 produtos, utilizando-se do mesmo espaço físico.

No entanto, a atuação da empresa concerne nas alterações sistêmicas que, segundo Van Den Berg e Zijm (1999), é definida como a redução dos níveis de inventários, para aumentar a velocidade e melhorar a eficiência de suas operações. Essas características têm fomentado flexibilidade, porém tem elevado os custos logísticos devido ao alto nível de serviço para o armazenamento dos insumos produtivos, sobretudo no seu setor de expedição.

Ainda, os estoques comprometem uma parte representativa dos ativos da empresa, representam cerca de $46 \%$ dos ativos totais. São considerados, pelo setor financeiro, os recursos imobilizados de maior investimento em valor econômico para a empresa (ROGERS et al, 2004; ARIAS et al., 2016). Por isso é primordial saber o quanto será comprado, ou qual o volume máximo a ser estocado para que não haja desperdício de material e consequentemente financeiro.

Assim, é importante a aplicação de ferramentas que beneficiem o controle e gerenciamento do estoque, equilibrando o nível de serviço no que diz respeito a possuir os insumos no e tempo na a quantidade certa. Neste sentido, o estudo pretende analisar a utilização de ferramentas de análise e de acompanhamento do estoque para aumentar a eficiência da empresa.

\section{Referencial teórico}

Nos últimos anos, a gestão de estoques tem se tornado um assunto muito importante tanto nos meios acadêmicos como na prática empresarial, pois seu planejamento e controle visam satisfazer às prioridades competitivas da organização, devido aos diversos custos envolvidos na decisão sobre estoques.

De acordo com Rogers et al. (2004), a forma como os estoques são gerenciados é diferente dos outros ativos e obrigações, tendo em vista que aqueles possuem uma dimensão física que deve ser levada em consideração. Todavia, como outros tipos ativos, os estoques representam custos significativos para as empresas e sua gestão eficiente torna-se fator essencial de competitividade (SOUZA et al., 2010).

\subsection{Sistema de Produção}

Em um ambiente globalizado, a busca pela sobrevivência têm despertado nas empresas o interesse em atingir satisfatórios níveis de eficiência nas suas operações e processos gerenciais, bem como a redução de custos. No entanto a definição de estratégias competitivas devem ser coerentes com o modelo a qual a produção é planejada, havendo uma racionalidade no sequenciamento das atividades de forma a sistematizar o processo.

Conforme Paladini et al. (2015), a abordagem sistêmica da qualidade foi criada a partir da teoria geral dos sistemas, viabilizando a utilização da estrutura sistemática planejar, organizar, dirigir e controlar a qualidade.

De acordo com esse contexto definir um sistema de produção pode gerar uma estratégia vital a competitividade da empresa. O sistema de produção é, conforme Slack et al. (2010), um conjunto de elementos planejados que visam à transformação de um insumo em produto. O mesmo sofre influências internas e externas da organização, que podem afetar o seu desempenho.

Soma se a isto a definição proposta por Paladini e Nogas (2013) que apenas as organizações bem definidas, cujas estruturas envolvem elementos que as caracterizem de determinada forma, com certo funcionamento e uma filosofia de atuação igualmente bem identificada podem ser classificadas como sistemas, caso contrário é uma estrutura qualquer.

Nesse contexto a definição por um sistema de produção auxilia a gestão a organizar todos os seus setores para realizar suas operações de produção, permitindo uma sequência lógica entre as etapas do processo produtivo alinhadas ao objetivo de produção da empresa, este deve estar alinhado às dimensões da produção, que 
caracterizam o processo produtivo.

As operações apesar de serem similares entre si atuando na transformação de recursos de input em output, diferem quanto ao perfil das dimensões da produção, que podem ser de volume, variedade, visibilidade e variação. Em paralelo a relação entre as operações viabiliza um modelo hierárquico do sistema de produção, propiciando o entendimento da articulação estratégica adiante a própria função produção.

Conforme Slack et al. (2010) e Santos et al. (2017), a estratégia de produção é definida a partir do conceito de hierarquia do sistema de produção. Desse modo, têm-se no nível da macro operação, a estratégia de produção definida como o padrão global de decisões e ações, que definem o papel, os objetivos e as atividades da produção de forma que apoiem e contribuam para a estratégia de negócios da organização.

No nível da micro operação, segundo os mesmos autores, estratégia de produção pode ser definida como o padrão global de decisões e ações que definem o papel, os objetivos e atividades de cada parte da produção de forma que apoiem e contribuam para a estratégia de produção do negócio. Desse modo desperta a necessidade de uma estratégia de operação.

\subsection{Filosofia Just-in-time (JIT)}

A superioridade das indústrias orientais frente aos seus concorrentes do ocidente foi amplamente reconhecida nos anos 80 , e tem servido de suporte para a nova postura estratégica das empresas nesta década de 90 . Este avanço dos orientais é reflexo de um modelo empresarial que remonta à década de 60 , sendo aperfeiçoada através dos anos, gerando o conceito, bastante abrangente, de filosofia Just-in-Time (JIT) de manufatura. A superioridade da filosofia JIT de manufatura se dá tanto no seu aspecto estratégico de flexibilidade da produção e rapidez de atendimento aos clientes, como nos seus objetivos econômico-financeiros de redução de custos, aumento de produtividade, garantia de qualidade, eliminação de desperdícios, entre outros (SILVEIRA; COUTINHO, 2008; SOUSA, 2017).

Foram identificados sete tipos de desperdícios que devem ser eliminados: desperdício de produção, desperdício de tempo de espera, desperdício de transporte, desperdício de estoque, desperdício de processamento, desperdício de movimento e desperdício de produtos defeituosos. Um dos objetivos do JIT, portanto, é fazer com que os estoques tendam a zero.

Os estoques são percebidos na filosofia JIT como quantidade de recursos a serem mantidos apenas para assegurar o fluxo de produção, portanto, reduzidos apenas a estoques de segurança (PASQUALI, 2010). Acrescese o papel da filosofia JIT na redução de desperdícios advindos custos de armazenagem, excesso de movimentações, ocupação de espaço desnecessários, com a redução de estoque, as perdas se tornam visíveis e passam a ser analisadas e corrigidas.

Voss (1987) diz que o JIT é uma abordagem disciplinada, que visa aprimorar a produtividade global e eliminar os desperdícios da produção. Ele possibilita a produção eficaz em termos de custo, assim como o fornecimento apenas da quantidade correta, no momento e local corretos, utilizando o mínimo de instalações, equipamentos, materiais e recursos humanos. O JIT é dependente do equilíbrio entre a flexibilidade do fornecedor e a flexibilidade do usuário. Ele é alcançado por meio da aplicação de elementos que requerem um envolvimento total dos funcionários e trabalho em equipe (GIANESI; BIAZZI, 2011).

Ludwig et al., (2016) desenvolveram uma pesquisa qualitativa aplicada abordagem os principais aspectos da implementação da filosofia Just in Time na redução de estoques em uma empresa do ramo moveleiro obtendo uma redução de $46 \%$ no nível de estoque, além da redução de perdas associadas aos níveis de estoque e um melhor aproveitamento do espaço físico destina para armazenagem.

\subsection{FIFO}

Uma boa e eficaz gestão é fundamental pra se obter crescimento e manutenção no mercado, para isto é essencial planejar, programar e controlar o que se produz. Segundo Sousa et al. (2016) ato de gerir recursos ociosos que possuem valor econômico e se destinam ao suprimento das necessidades futuras de material, numa organização, é crucial na manutenção dos serviços. O autor afirma ainda que o que se busca periodicamente é o equilíbrio entre nível de estoque ideal e redução de custos de manutenção dos estoques.

Pierskalla e Roach (1975) apresentaram a contribuição do FIFO na minimização dos custos totais de manutenção de estoque. Minner e Transchel (2010) utilizaram o FIFO para apoiar o desenvolvimento de um método para determinar quantidades de pedidos dinâmicos para produtos perecíveis com multiplas restrições de nível de serviço. 
Pozo et al. (2015) propõe que se preveja o valor do estoque em intervalo de tempo adequado para gerenciá- lo, pois dessa forma será possível comparar o planejado versus o executado, para assim tomar as devidas ações quando surgir possíveis desvios.

Essa avaliação é realizada tomando como base nos preços dos itens que estao em estoque. O valor real de estoque é feito por dois processos; por meio do inventario físico e por um controle das fichas de cada item, ou seja ocorre a estipulação dos preços dos produtos para que assim ocorre uma gestao integrada da empresa, podendo-se avaliar os estoques pelos métodos de Custo Médio, Primeiro a entrar primeiro a sair - FIFO e Último a entrar primeiro a sair - UEPS (Slack et al., 2010).

Para tal pesquisa utilizou-se o método FIFO ou seja um controle de estoque, que indica o momento correto de ser retirado do almoxarifado, ou seja o item que primeiro entrou e que está há mais tempo no setor, proporcionando um maior controle de produtos pois reduz a possibilidade de haver itens que passaram do prazo de validade e, portanto, descartados, prejudicando a empresa nos mais diversos fatores.

\subsection{Custos dos Estoques}

Muitas vezes, os custos relativos a estoques são ignorados pelos gestores, e pode ter como consequência o enfraquecimento dos negócios, principalmente para as empresas que operam com margens de lucro relativamente baixas. Saber os custos incorridos da decisão de manter ou não estoques é essencial para os gestores realizarem a tomada de decisão.

Segundo Ballou (2004), há três categorias diferentes de custos na administração de inventário: os custos de manutenção, os custos de requisição ou compra e os custos de falta de estoques.

Os custos de manutenção de estoque estão associados a todos os custos necessários para manter certa quantidade de mercadorias por um período de tempo. Há, em primeiro lugar, o custo de oportunidade do capital, pois estoque imobiliza capital que poderia ser empregado de forma diferente dentro ou fora da firma. Em segundo lugar, existem custos associados aos impostos e aos seguros (contra incêndio e roubo, por exemplo). Os custos da armazenagem física propriamente dita são o terceiro tipo, são aqueles relacionados com a quantidade de estoque mantido. Existem, finalmente, os custos associados ao risco de manter o estoque. São os custos de perdas devidas a deterioração, obsolescência, dano e furto (BALLOU, 2004; SOUSA et al., 2017).

Os custos de compra estão associados ao processo de aquisição das quantidades requeridas para reposição do estoque. Os custos de aquisição incluem o custo de processar pedidos nos departamentos de compras, faturamento e contabilidade; o custo para enviar o pedido até o fornecedor; o custo de preparação da produção (set-up) ou do manuseio para atender ao lote solicitado; o custo devido a qualquer tipo de manuseio ou processamento realizado na doca de recepção; e o preço da mercadoria (SLACK et al., 2010).

Os custos de falta são aqueles que ocorrem caso haja demanda por itens em falta no estoque. Conforme a reação do cliente potencial a uma situação de carência, podem ocorrer dois tipos de custos de falta: custos de vendas perdidas e custos de atrasos. Os custos de vendas perdidas ocorrem quando um cliente cancela seu pedido caso o produto desejado esteja em falta. Este custo pode ser estimado como o lucro perdido na venda agregado de qualquer perda de lucro futuro, devido ao efeito negativo que essa falta possa ter na boa vontade do cliente. Já os custos de atrasos resultam em gastos diretos da empresa, pois o atraso pode acarretar gasto adicional devido a custos administrativos e de vendas no reprocessamento do pedido, além de custos extraordinários de transporte e manuseio, caso o suprimento deva ser realizado fora do canal normal de distribuição. Produtos que podem sofrer atrasos são aqueles considerados bastante diferenciados pelo cliente (BALLOU, 2004).

Os custos intangíveis, que são relacionados com a perda da imagem devido ao não atendimento dos requisitos dos clientes, também devem ser considerados. Segundo Rufino e Andrade Júnior (2014) e Sousa et al., 2017 esses custos são chamados de custos estimados da qualidade, pois são todos os custos que não podem ser mensurados objetivamente, e sim através de estudos, pesquisas e critérios subjetivos. Esses custos nada mais são do que custos das falhas externas de difícil mensuração. Os custos das falhas externas são a categoria de custos da qualidade que mais merece a atenção dos administradores, justamente por estarem, muitas vezes, associados à reputação da empresa junto à sociedade.

Para Kaminski (2010) um menor custo de estoque está associado a redução dos desperdícios de estoque com custo de transporte, oportunidade, imobilizado e de armazenagem, desse modo, algumas das principais características do JIT como a produção puxada auxilia tanto no controle da qualidade dos componentes como na eliminação desses desperdícios com a entrega de componentes no tempo certo diretamente na linha. 


\subsection{Curva ABC}

O método da curva $\mathrm{ABC}$, proposto pelo economista e sociólogo Vilfredo Pareto, logo após a Segunda Guerra Mundial, teve sua origem a partir de estudos estatísticos sobre a renda de pessoas de diversos países ressaltando a existência de uma lei geral de má distribuição, ou seja, ele comprovou que uma pequena parcela da população absorvia uma grande porcentagem de renda, restando uma parte significativamente menor de renda para a que representava o maior percentual da população (ROGERS et al, 2004; ARIAS et al., 2016).

Esta pode ser entendida como uma importante ferramenta que auxilia o administrador pois permite a identificação de itens que requerem maior atenção e tratamento diferenciado comparado a outros, ou seja estabelece formas de gestão apropriadas à importância de cada item em relação ao valor total dos estoques. Nemrajela e Mvohwa (2016) destacam o suporte dessa ferramenta para os gestores na identificação de itens críticos ao se esgotar na organização.

Ela tem sido utilizada para as mais diversas funções: gestão de estoques, definição de políticas de vendas, estabelecimento de prioridades para a programação da produção e diversos outras dificuldades usuais na empresa. Nallusamy et al. (2017) propuseram uma política de revisão periódica de estoque através da classificação $\mathrm{ABC}$ desenvolvendo um modelo a fim de direcionar e controlar os itens de inventário em uma industria de manufatura automotiva, os resultados obtiveram uma melhoria no índice de rotatividade de estoque ao controlar as matérias-primas de forma mais eficiente. Logo, a partir do sistema de análise $\mathrm{ABC}$ os gestores podem planejar o suprimento dos estoques focando os elementos que dentro de um todo são indispensáveis para o funcionamento contínuo das atividades da empresas em gerais (MILANI et al., 2015).

A redução do capital imobilizado em estoque tem sido reconhecido como relevante contribuição da ferramenta por permitir aos gestores maior flexibilidade quanto a utilização de recursos financeiros, além de evitar problemas associados ao armazenamento de produtos, tais como obsolecência, depreciação, desgaste, custos de armazenamento, dentre outros. Kampf e Lorincová (2016) aplicaram a análise $\mathrm{ABC}$ em uma indústria do setor automotivo da Eslováquia com o objetivo de reduzir custos associados aos estoques, propondo uma proposta que permita às empresas reduzir a disparidade entre aquisição de materiais e seu consumo mensal, identificando a oportunidade de reduzir o capital imobilizado por meio da redução de estoques.

\section{Metodologia}

O presente trabalho foi desenvolvido em conjunto com os gestores do setor de expedição visando a realização de um diagnóstico do sistema atual e, posteriormente, a indicação sugestões de melhoria dos processos atuais. Segundo Rudio (2015), essa metodologia é denominada de avaliação formativa.

Os dados foram coletados por meio de fontes primárias e secundárias. Os dados de vendas, que compreende o período de 2012 a 2014, foram coletados através de relatórios gerados pelo sistema, de documentos e manuais existentes na empresa no setor de expedição. Posterior à coleta, os dados foram tratados e analisados de acordo com indicadores de estoque referenciados com base nas contribuições de Slack et al. (2010).

Em seguida foi desenvolvida uma planilha no software Excel com todos os procedimentos de cálculo necessários ao tratamento dos dados. Neste sentido, o presente trabalho apresenta as análises e as melhorias em três vertentes: Controle da programação FIFO; Classificação $\mathrm{ABC}$ do estoque e representação gráfica do layout.

\subsection{Descrição da Empresa}

A empresa estudada atua no ramo de produção de bens alimentícios há mais de 40 anos e sua matriz está localizada no município de Caruaru - PE. Ela possui um mix de mais de 130 produtos dentre massas, biscoitos, mistura para bolo, café e condimentos. O setor em análise por este trabalho é o de expedição, que é responsável pelas operações de movimentação e estoque. Apesar da empresa utilizar logística própria, ela não possui um sistema integrado de gestão e de controle de estoque bem estruturado. As atividades de movimentação de produtos seguem o seguinte fluxo (Figura 1):

É importante destacar que o setor estudado apresenta um nível de conformidade, identificado nos inventários mensais, dos meses de maio até julho de 2015 , próximo a 99,86\%. As práticas de balanceamento (atribuição de tarefas de modo que cada célula produtiva ou estação de trabalho tenha o mesmo tempo de execução) favorecem essa conformidade, demostrando que esse valor não condiz com a realidade encontrada e tornando perceptível a necessidade de melhorias que auxiliem no processo de controle e gestão do estoque melhorando significativamente a eficiência e a confiabilidade das atividades do setor de expedição. 


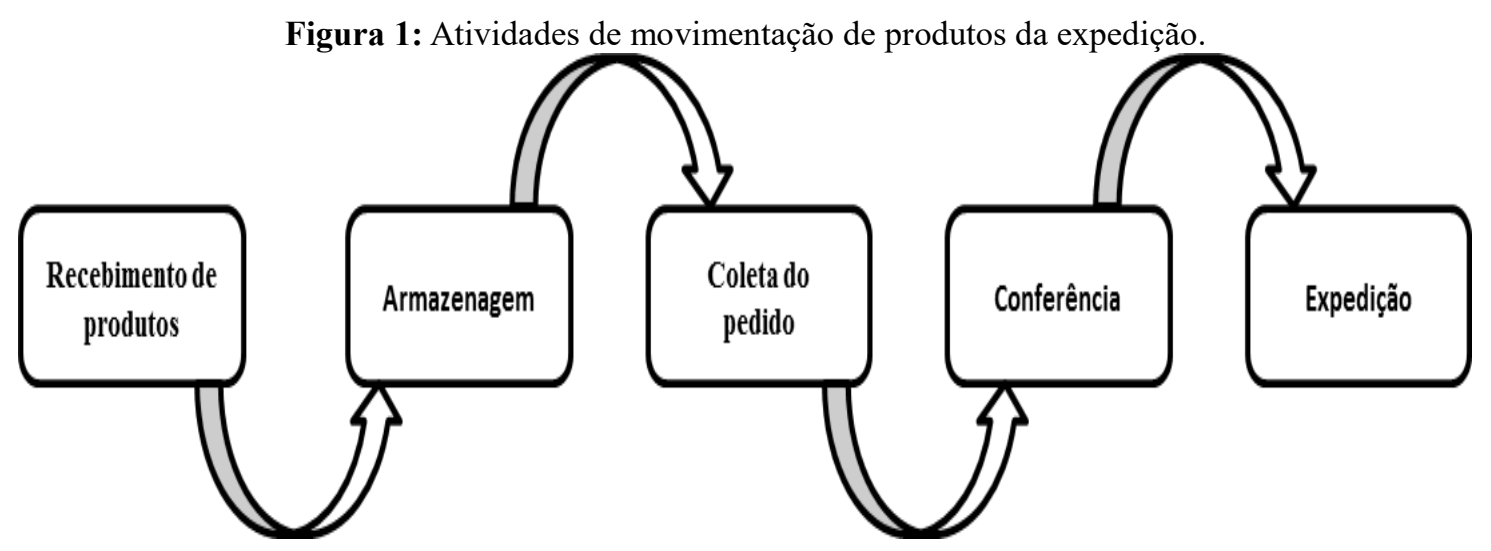

Além do mais, os gestores lidam com a falta de autonomia no controle de validade dos produtos advindos de transferência da fábrica (etapa de conferência), nesse sentido ocorre a transferência de produtos com prazo de vencimento menores ao dos produtos já existentes na expedição, havendo um contra fluxo e necessitando uma nova reorganização dos lotes.

\section{Análise da Empresa}

\subsection{Análise do Método de Trabalho}

O método utilizado pela empresa para o controle de validade é o FIFO que tem com o objetivo sequenciar a saída de produtos conforme o prazo de validade. No entanto, o controle restringe-se apenas ao posicionamento dos lotes conforme o período de chegada do produto ao estoque, havendo divergências nas datas de produção.

Deve-se salientar que há dificuldade na execução dessa política devido a ausência de padronização no endereçamento dos produtos e a inexistência de um padrão de localização. Ocasionando o posicionamento inadequado de lotes na área de armazenagem. Há ainda ausência de acompanhamento da saída de produtos, pois não existe controle das datas remanescentes. Os dois problemas juntos dificultam a sequência de separação do pedido, neste ponto ao desordenar a sequência dos mesmos no pallet de coleta acarretava erro no procedimento de conferência que ocasionava problema de inversão de estoque e assim da política FIFO. Segundo Silveira e Coutinho (2008), a ausência de método de trabalho impõe sérios problemas quanto a eficiência, controle, satisfação, qualidade do trabalho e avaliação da produtividade do setor.

\subsection{Controle de Estoque}

O controle de estoque utilizado pela empresa é realizado por meio de software próprio que indica as quantidades disponíveis no sistema, bem como uma previsão média de estoque baseada nas demandas referentes aos três últimos meses. No entanto, a discrepância observada entre os níveis de estoque indicados no sistema e o estoque físico retoma a necessidade de contar diariamente todo o estoque, esta atividade tem duração de uma hora e trinta minutos com a utilização de três colaboradores e um supervisor de expedição.

A reposição de estoque dos produtos que são produzidos na matriz é de única e exclusiva responsabilidade do planejamento e controle da produção (PCP). Ainda ocorrem problemas como a falta de determinados produtos e a necessidade de devolução de produtos por falta de estoque na matriz.

\subsection{Layout}

A atual forma de armazenagem utiliza paradigmas estabelecidos no consenso dos colaboradores de forma a não priorizar grupos de produtos semelhantes ou em sequência, conforme a lista de separação. Esse fato corrobora para uma demasiada movimentação na separação de pedidos, segundo Gianesi (1998), essa atividade intensiva compromete cerca de $30 \%$ a $40 \%$ do custo do setor de expedição.

No caso da empresa em estudo, não há coerência entre a sequência de separação emitida por meio de documento do setor de vendas com o real posicionamento dos produtos no estoque e ainda há falta de endereçamento dos produtos e distanciamento de produtos semelhantes. Fazendo com que os funcionários tenham de percorrer grandes distâncias e ter um conhecimento especifico de cada tipo de produto.

O atual layout (Figura 2-A) apresenta a dificuldade de controlar as quantidades dos produtos devido ao posicionamento desalinhado dos pallets, comprometendo o procedimento de contagem, dificultando o controle do vencimento dos produtos devido a diversidade de lotes que chegam de forma desordenada e afetando diretamente nas atividades de rotina como contagem, separação e reabastecimento dos produtos. Os valores 
indicados nas áreas de cor cinza na Figura 2 referem-se as quantidades de pallets nas suas respectivas seções, que com a atual distribuição do layout viabiliza o posicionamento de 1.157 pallets de medida padrão ( $1 \mathrm{~m} \mathrm{x}$ $1,20 \mathrm{~m})$, com a distribuição de produtos conforme está demonstrado na Figura 2-B.

Figura 2: Layout e posicionamento dos produtos atuais

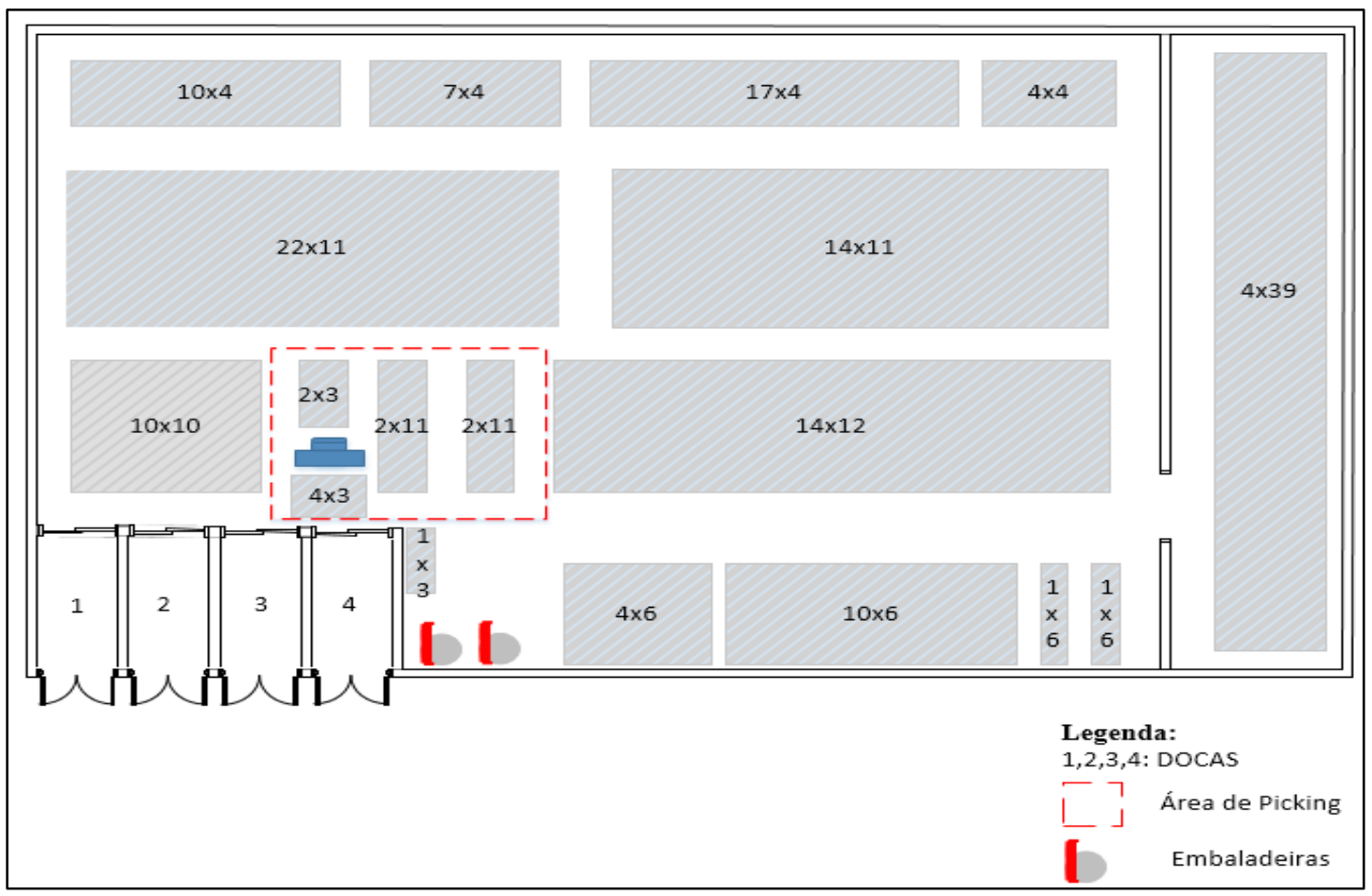

(A)

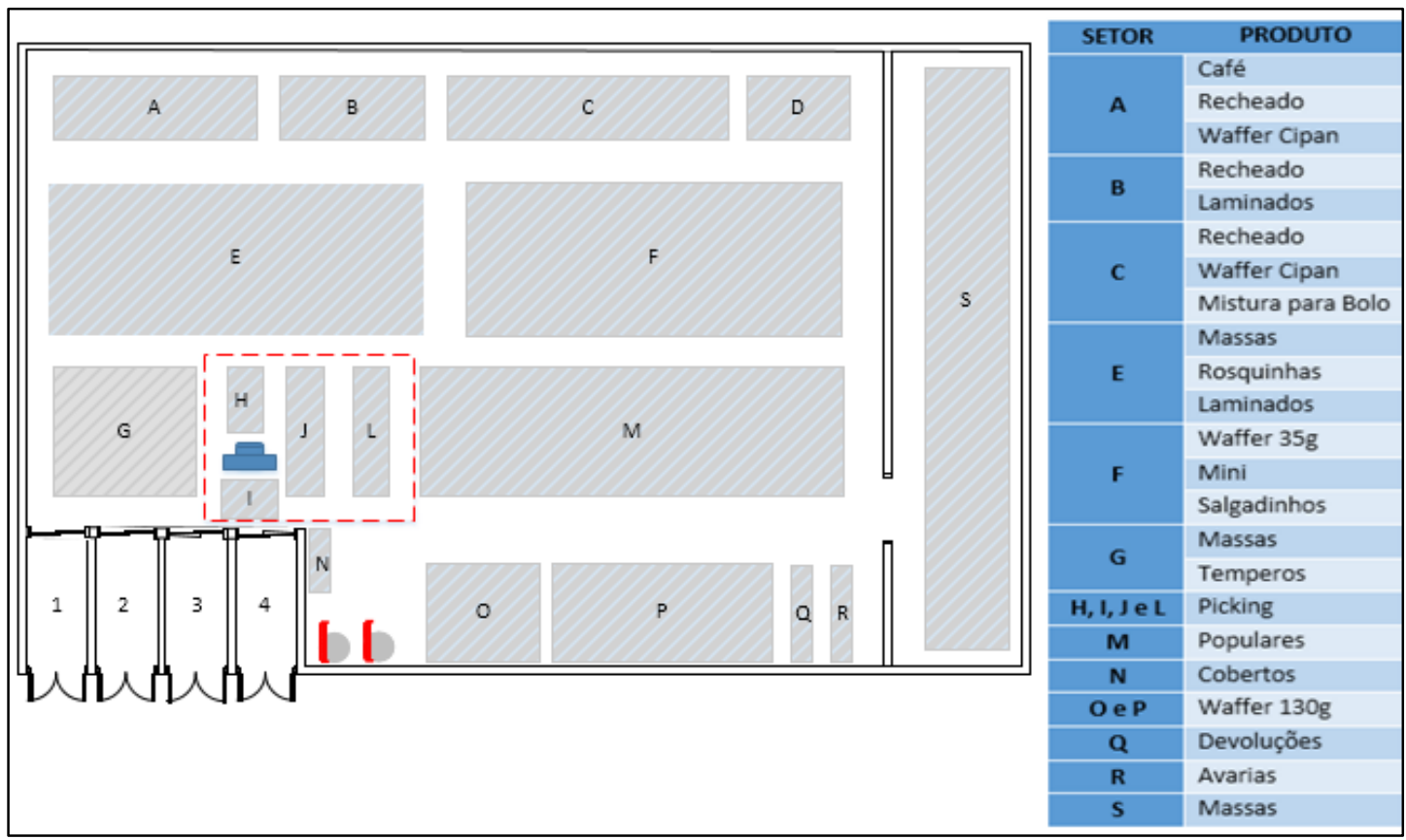

(B)

O crescente mix de produtos e a limitação de espaço devido à ausência de investimentos na aquisição de estruturas verticais para o armazenamento de produtos reforça a necessidade de forma mais objetiva que, faz 
com que a eficiência do processo aumente e reduza os custos.

No entanto, torna-se necessário realizar o controle da quantidade estocada, conservando a qualidade dos materiais e mantendo uma identificação clara dos materiais afim de sistematizar as informações para que sua interpretação e acesso sejam rápidos e eficazes. Isso requer um layout bem estruturado, segundo Bueno e Alencar (2016), certos fatores devem ser considerados: grau de acesso ao material, modelos de fluxo de material, locais de área obstruídas, a eficiência da mão-de-obra e a segurança do pessoal e do armazém.

Desse modo, foi realizado um estudo para quantificar a necessidade de acessos para o manuseio dos produtos e a quantidade de espaço disponível propondo melhoria no atual layout ampliando a área de estocagem e segmentando a armazenagem por tipo de produto, como será apresentado na próxima seção.

\section{Sugestões de Melhorias}

O uso eficiente e eficaz de um controle dos níveis de estoque é necessário para uma aplicação racional dos recursos financeiros disponíveis pela organização, para isso se faz necessário a racionalização das tomadas de decisão baseadas na política do FIFO, o acompanhamento e o controle de estoque.

Em posse dos principais indicadores de níveis de estoque, estima-se a redução nos custos de movimentação que abrangem despesas fisscais, capital imobilizado, transporte, mão-de-obra e redução de avarias, bem como propicia o incremento na confiabilidade de estoque devido a melhoria no nível de serviço prestado. Por outro lado, sua implementação requer um período de adaptação para eventuais ajustes, conforme sua realidade e a necessidade devido a interferência de fatores externos.

Com a utilização do tempo de cobertura (TC) como indicador do tempo de reposição e do tempo de ressuprimento, será possível constatar alguns efeitos quando da alteração de seus valores:

- A diminuição da quantidade de produtos transferidos e do intervalo de transferências, gerando o aumento da frequência das compras e, como consequência, diminuição do tamanho das transferências, estoque médio e o tamanho do estoque máximo, como também aumento da rotatividade;

- Redução do prazo de entrega acarretando na diminuição do estoque mínimo e do ponto de pedido;

- As transferências ao serem realizadas conforme a estimativa de demanda, diminui-se o risco de investimentos desnecessários e mantém um nível de atendimento satisfatório sem comprometer a capacidade de estoque.

Sugere-se ainda que o controle do estoque mínimo atenderá o fluxo da demanda até o momento que os estoques sejam repostos sem excessos sob um nível de segurança. A forma como esses modelos serão geridos e implantados podem apresentar resultados mais satisfatórios quando complementado com a definição de uma política de gestão.

Em análise as diversas áreas que influenciam de forma direta e indireta no setor de expedição, foi realizada uma análise sobre os aspectos a serem melhorados de modo a agregar eficiência ao processo da expedição, conforme Quadro 1.

Quadro 1: Pontos de melhoria

\begin{tabular}{|c|c|c|}
\hline Área & Pontos de melhoria & Solução \\
\hline \multirow{5}{*}{ Gestão } & $\begin{array}{l}\text { Não há informações prévia de pedidos e } \\
\text { transferências }\end{array}$ & \multirow{2}{*}{$\begin{array}{l}\text { Integração entre setores de PCP, Produção e } \\
\text { Expedição para expor e discutir o planejamento da } \\
\text { semana }\end{array}$} \\
\hline & $\begin{array}{l}\text { O setor não é responsável pelo seu } \\
\text { abastecimento }\end{array}$ & \\
\hline & Ausência de autonomia na gestão & $\begin{array}{l}\text { Impor novas responsabilidades e autonomia para o } \\
\text { gerenciamento do setor }\end{array}$ \\
\hline & Falta de cobrança de planejamento & $\begin{array}{l}\text { Estabelecimento de metas e objetivos a serem } \\
\text { alcançados }\end{array}$ \\
\hline & Ausência de filosofia de melhoria contínua & $\begin{array}{l}\text { Realização de reuniões de acompanhamento de } \\
\text { metas }\end{array}$ \\
\hline \multirow{2}{*}{ Treinamento } & Capacitação & \multirow{2}{*}{$\begin{array}{l}\text { Necessita-se de treinamento voltados para a } \\
\text { explanação de métodos de controle de estoque, }\end{array}$} \\
\hline & Organização & \\
\hline
\end{tabular}




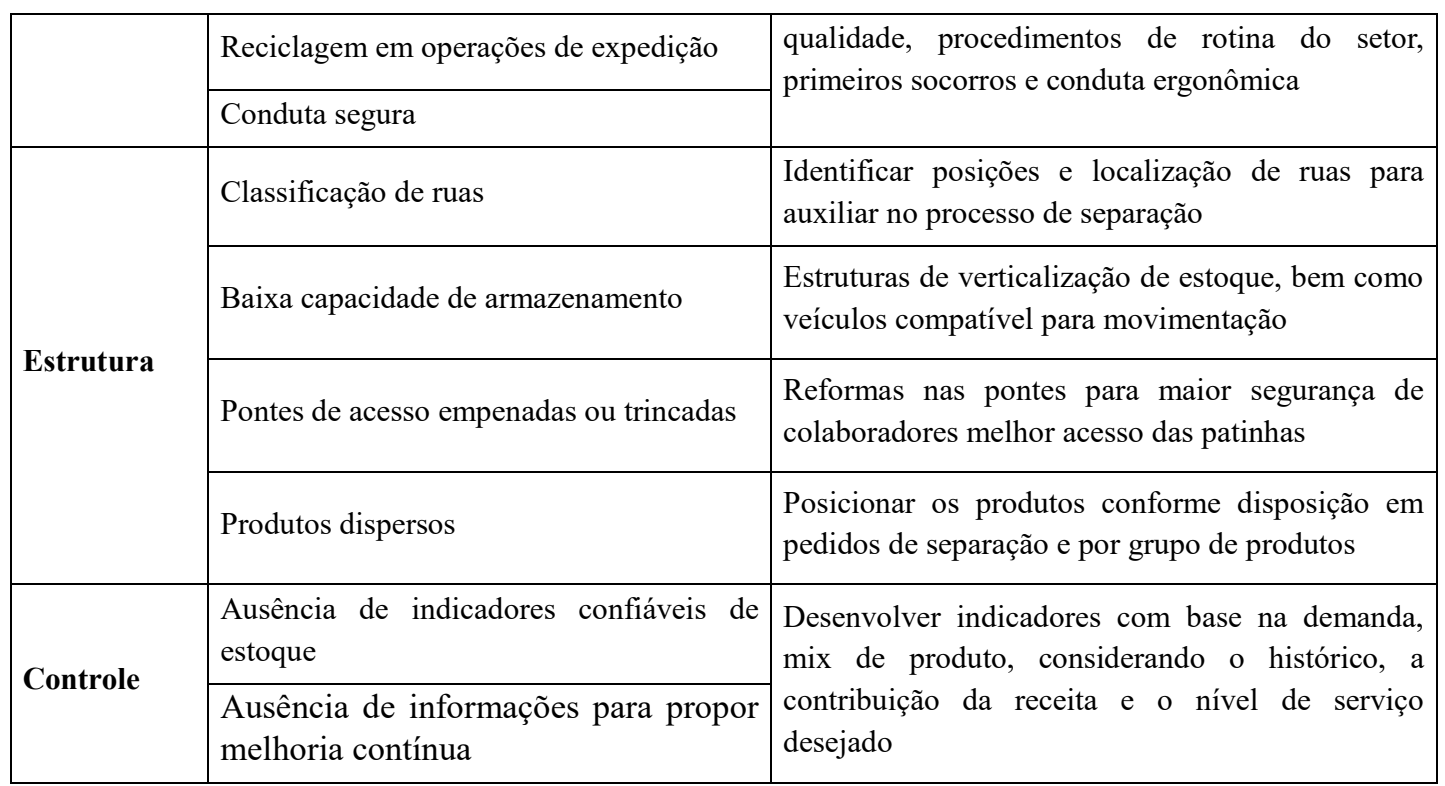

A seguir tem-se sugestões específicas para os três pontos críticos supracitados na seção anterior.

\subsection{Análise do Método de Trabalho}

A padronização do método é uma forma eficaz de otimizar pela padronização das atividades: abastecimento de picking, separação, carregamento, manuseio de equipamentos e conferência. Implicando resultados de melhoria a curto prazo em:

- Redução de danos em produtos e equipamentos e aumento da durabilidade dos equipamentos utilizados: através do treinamento quanto a utilização e condução de equipamentos de transporte e dos modos de armazenagem (BALLOU, 2004).

- Redução no tempo de separação, inventário, carregamento e conferência: a utilização de um método de organização do layout e de acompanhamento de estoque viabilizará um procedimento único de separação com menos movimentações e facilitará o processo de conferência evitando erros de inversões de estoque, como também melhoraria a visibilidade e o controle de posicionamento dos produtos, tornando mais rápido o procedimento de inventário (BARTHOLDI; HACKMAN, 2010).

- Controle da política FIFO: a utilização de uma planilha que forneça os lotes mais próximos ao vencimento facilitará o controle de datas no estoque (SLACK et al., 2010; SINGH; SINGH, 2015).

- Distribuição e acesso de carga em caminhões: a definição de um padrão de armazenamento de produtos conforme seu volume, peso e quantidade facilitará o acesso para os descarregadores diminuindo o tempo de entrega (CRUZ et al, 2015; ANDRIOLI et al., 2015 SPERANZA, 2016).

- Confiabilidade de estoque: o controle e acompanhamento dos níveis de estoque permitirá uma melhor gestão do mesmo, incrementando na capacidade de atendimento de pedidos (SLACK et al., 2010).

\subsection{Controle de Estoque}

Em virtude da necessidade de itens estocados, é indispensável a utilização de ferramentas de controle para que se possa eliminar ao máximo as incertezas. Os indicadores mais indicados para auxiliar a gestão da expedição da empresa são:

- Ponto de pedido: representa a quantidade, em estoque, que determinado produto atinge para que dispare o processamento do pedido de reposição do mesmo em tempo hábil (SLACK et al., 2010);

- Estoque mínimo ou de segurança: tem propósito de compensar as variações naturais no prazo de fornecimento ou na quantidade demandada. Slack et al. (2010) comenta que o cálculo de estoque de segurança é determinado com relação à probabilidade de não faltar o produto.

- Estoque máximo: o estoque máximo é definido, segundo Slack et al. (2010), pela quantidade máxima de estoque permitida para o material, desde que seja suficiente para o consumo em certo período releve 
o tempo de aquisição, a área de armazenagem e a disponibilidade financeira.

- Giro de estoque ou rotatividade: indica quantas vezes o estoque de determinado produto foi renovado ao longo de um período. Informação relevante para a tomada de decisões com relação a investimentos nos estoques e estratégias de venda (SOUZA et al., 2010; AQUINO et al., 2017).

- Tempo ou taxa de cobertura: é o período em que o estoque será suficiente para cobrir a demanda Slack et al. (2010).

Os cálculos realizados para a obtenção desses indicadores foram programados em uma planilha eletrônica cuja apresenta seus resultados conforme Tabela 2. No entanto há discrepância observada entre os níveis de estoque considerados ideais segundo os métodos científicos e os identificados na empresa. Fato que é justificado pela ausência de regras claras a respeito do controle de estoques, reforçando a necessidade de um instrumento de acompanhamento do estoque.

Objetivando prover informações de acompanhamento e controle acerca das quantidades, localização e vencimento dos produtos foi desenvolvido uma planilha de controle de estoque conforme apresenta a Tabela 1. O funcionamento versa em duas atividades, a primeira consiste em cadastrar informações de vencimento, localização e quantidade do produto no momento de entrada do mesmo no estoque, já a segunda refere-se a retirada das quantidades dos produtos cadastrados conforme relatório diário de vendas.

Tabela 1: Planilha de controle de estoque

\begin{tabular}{|c|c|c|c|c|c|c|c|}
\hline Quantidade & & 64572 & & & & & 64572 \\
\hline Produto & \multicolumn{4}{|l|}{ Biscoito 1} & & & \\
\hline Localização & & & Vagas ocupadas & 1 & Vencimento & $12 / 12 / 2015$ & \\
\hline Validade & & $12 / 12 / 2015$ & & & & & Total \\
\hline Quantidade & & 23154 & & & & & 23154 \\
\hline Produto & \multicolumn{4}{|l|}{ Biscoito 2} & & & \\
\hline Localização & & & Vagas ocupadas & 1 & Vencimento & $13 / 02 / 2016$ & \\
\hline Validade & & $13 / 02 / 2016$ & & & & & Total \\
\hline Quantidade & & 23645 & & & & & 23645 \\
\hline Produto & \multicolumn{4}{|l|}{ Biscoito 3} & & & \\
\hline Localização & & & Vagas ocupadas & 1 & Vencimento & $24 / 03 / 2016$ & \\
\hline Validade & $24 / 03 / 2016$ & & & & & & Total \\
\hline Quantidade & 23154 & & & & & & 23154 \\
\hline Produto & \multicolumn{4}{|l|}{ Biscoito 4} & & & \\
\hline Localização & & & Vagas ocupadas & 1 & Vencimento & $19 / 09 / 2016$ & \\
\hline Validade & $19 / 09 / 2016$ & & & & & & Total \\
\hline Quantidade & 23654 & & & & & & 23654 \\
\hline Produto & \multicolumn{4}{|l|}{ Biscoito 5} & & & \\
\hline Localização & & & Vagas ocupadas & 1 & Vencimento & $12 / 12 / 2016$ & \\
\hline Validade & $12 / 12 / 2016$ & & & & & & Total \\
\hline Quantidade & 23645 & & & & & & 23645 \\
\hline Produto & \multicolumn{4}{|l|}{ Biscoito 6} & & & \\
\hline Localização & & & Vagas ocupadas & 1 & Vencimento & $25 / 11 / 2015$ & \\
\hline Validade & $25 / 11 / 2015$ & & & & & & Total \\
\hline Quantidade & 134 & & & & & & 134 \\
\hline Produto & \multicolumn{4}{|l|}{ Biscoito 7} & & & \\
\hline Localização & & & Vagas ocupadas & 1 & Vencimento & $18 / 11 / 2015$ & \\
\hline
\end{tabular}




\begin{tabular}{|l|l|l|l|l|l|l|l|l|}
\hline Validade & $18 / 11 / 2015$ & & & & & & & Total \\
\hline Quantidade & 46513 & & & & & & & 46513 \\
\hline
\end{tabular}

Na Tabela 2 são apresentados as quantidades e valores para os indicadores de controle de estoque anteriormente citados. Estes resultados foram obtidos com base nos dados de vendas fornecidos pela empresa referente ao período de 2012 a 2014.

O acompanhamento desta planilha (Tabela 2) deve ser realizado diariamente verificando os indicadores para avaliar o estoque.

Tabela 2: Relatório geral

\begin{tabular}{|c|c|c|c|c|c|c|c|c|c|c|c|}
\hline & ACOMP & ANHA & MENTO & & & & & ÍNDICES & E ESTO & QUE & \\
\hline Produto & $\begin{array}{l}\text { Validad } \\
\text { e }\end{array}$ & \begin{tabular}{|l|} 
Dias \\
P/ \\
Venc \\
.
\end{tabular} & Situação & Unid & $\begin{array}{l}\text { Estoqu } \\
\text { e Atual }\end{array}$ & $\begin{array}{l}\text { Ponto } \\
\text { de } \\
\text { Pedid } \\
\text { o }\end{array}$ & $\begin{array}{l}\text { Nível } \\
\text { de } \\
\text { Estoqu } \\
\text { e }\end{array}$ & $\begin{array}{l}\text { Seguranç } \\
\text { a }\end{array}$ & $\begin{array}{l}\text { Máxim } \\
\text { o }\end{array}$ & Giro & $\begin{array}{l}\text { TC(dias } \\
\text { ) }\end{array}$ \\
\hline Biscoito 1 & $16 / 05 / 16$ & 187 & $\begin{array}{l}\text { Prazo - } \\
\text { Menos de } \\
12 \text { meses }\end{array}$ & FD & 2504 & 2815 & $\begin{array}{l}\text { Fazer } \\
\text { Pedido }\end{array}$ & 1346,46 & 4161,14 & 38,6 & 9 \\
\hline Biscoito 2 & $12 / 12 / 15$ & 31 & \begin{tabular}{|l|} 
Prazo - \\
Menos de \\
3 meses
\end{tabular} & FD & 2925 & 987 & $\begin{array}{l}\text { Estoque } \\
\text { Ideal }\end{array}$ & 434,19 & 1420,76 & 12,1 & 30 \\
\hline Biscoito 3 & $13 / 02 / 16$ & 94 & $\begin{array}{l}\text { Prazo - } \\
\text { Menos de } \\
6 \text { meses }\end{array}$ & FD & 668 & 365 & $\begin{array}{l}\text { Estoque } \\
\text { Ideal }\end{array}$ & 209,13 & 573,87 & 18,0 & 20 \\
\hline Biscoito 4 & $24 / 03 / 16$ & 134 & $\begin{array}{l}\text { Prazo - } \\
\text { Menos de } \\
6 \text { meses }\end{array}$ & CX & 315 & 120 & $\begin{array}{l}\text { Estoque } \\
\text { Ideal }\end{array}$ & 73,18 & 193,40 & 8,8 & 41 \\
\hline Biscoito 5 & $19 / 09 / 16$ & 313 & $\begin{array}{l}\text { Prazo - } \\
\text { Menos de } \\
12 \text { meses }\end{array}$ & FD & 293 & 144 & $\begin{array}{l}\text { Estoque } \\
\text { Ideal }\end{array}$ & 88,21 & 232,40 & 11,9 & 31 \\
\hline Biscoito 6 & $12 / 12 / 16$ & 397 & $\begin{array}{l}\text { Prazo - } \\
\text { Mais de } \\
\text { um ano }\end{array}$ & FD & 164 & 430 & $\begin{array}{l}\text { Fazer } \\
\text { Pedido }\end{array}$ & 283,64 & 713,96 & $\begin{array}{l}35,5792 \\
7\end{array}$ & 10 \\
\hline Biscoito 7 & $25 / 11 / 15$ & 14 & $\begin{array}{l}\text { Prazo - } \\
\text { Menos de } \\
\text { um mês }\end{array}$ & CX & 425 & 130 & $\begin{array}{l}\text { Estoque } \\
\text { Ideal }\end{array}$ & 70,57 & 200,59 & $\begin{array}{l}8,15058 \\
8\end{array}$ & 45 \\
\hline Biscoito 8 & $18 / 11 / 16$ & 373 & $\begin{array}{l}\text { Prazo - } \\
\text { Mais de } \\
\text { um ano }\end{array}$ & CX & 645 & 605 & $\begin{array}{l}\text { Estoque } \\
\text { Ideal }\end{array}$ & 298,86 & 3551,15 & $\begin{array}{l}39,9023 \\
3\end{array}$ & 9 \\
\hline Biscoito 9 & $17 / 01 / 16$ & 67 & $\begin{array}{l}\text { Prazo - } \\
\text { Menos de } \\
3 \text { meses }\end{array}$ & $\mathrm{CX}$ & 2410 & 2301 & $\begin{array}{l}\text { Estoque } \\
\text { Ideal }\end{array}$ & 1250,34 & 3109,03 & $\begin{array}{l}34,0514 \\
5\end{array}$ & 11 \\
\hline $\begin{array}{l}\text { Biscoito } \\
10\end{array}$ & $13 / 08 / 15$ & -90 & $\begin{array}{l}\text { VENCE } \\
\mathbf{U}\end{array}$ & $\mathrm{CX}$ & 1934 & 2046 & $\begin{array}{l}\text { Fazer } \\
\text { Pedido }\end{array}$ & 1063,04 & 919,82 & $\begin{array}{l}40,3076 \\
5\end{array}$ & 9 \\
\hline $\begin{array}{l}\text { Biscoito } \\
11\end{array}$ & $14 / 07 / 16$ & 246 & $\begin{array}{l}\text { Prazo - } \\
\text { Menos de } \\
12 \text { meses }\end{array}$ & CX & 1205 & 632 & $\begin{array}{l}\text { Estoque } \\
\text { Ideal }\end{array}$ & 287,78 & 291,13 & $\begin{array}{l}20,5958 \\
5\end{array}$ & 18 \\
\hline
\end{tabular}

Outra forma de controlar o estoque é por meio da utilização da classificação ABC. Ela foi aplicada com o objetivo classificar gerencialmente os produtos, podendo determinar a importância de cada item dentro do 
estoque, conforme sua participação no faturamento da empresa, rotatividade, valor alto e volume de vendas (BENITO e CLAY, 1988). Segundo Slack et al. (2010), os resultados da classificação serão segmentados em grupos divididos em três classes, como segue:

- Classe A: itens que possuem alto valor de demanda ou consumo.

- Classe B: itens que possuem um valor de demanda ou consumo intermediário.

- Classe $\mathrm{C}$ : itens que possuem um valor de demanda ou consumo baixo.

A identificação dos produtos que devem receber maior atenção no gerenciamento dos estoques advém do agrupamento de produtos conforme performance de participação de produtos na receita empresa, para a obtenção desses resultados foram utilizados os relatórios de vendas do período de 2012 a 2014. Os resultados de 2015 não foram utilizados devido a insuficiência de informações acerca das vendas do período estudado.

A abordagem de classificação pelo preço de venda, representada no Gráfico 1, demonstra que 19,66\% dos itens classificam-se como "A". Esses representam uma importância significativa, pois trazem maior retorno financeiro totalizando $75,60 \%$ da receita no ano de 2014 .

Reforça-se a necessidade de organizar os produtos de classificação A nas zonas mais próximas as docas devido a recorrente necessidade de acesso ocasionada pela sua alta participação nas vendas, já os demais produtos de classificação B e C se localizarão em regiões posteriores em sequência a sua classe (STANLEY et al., 2004).

Gráfico 1: Classificação ABC para 2014

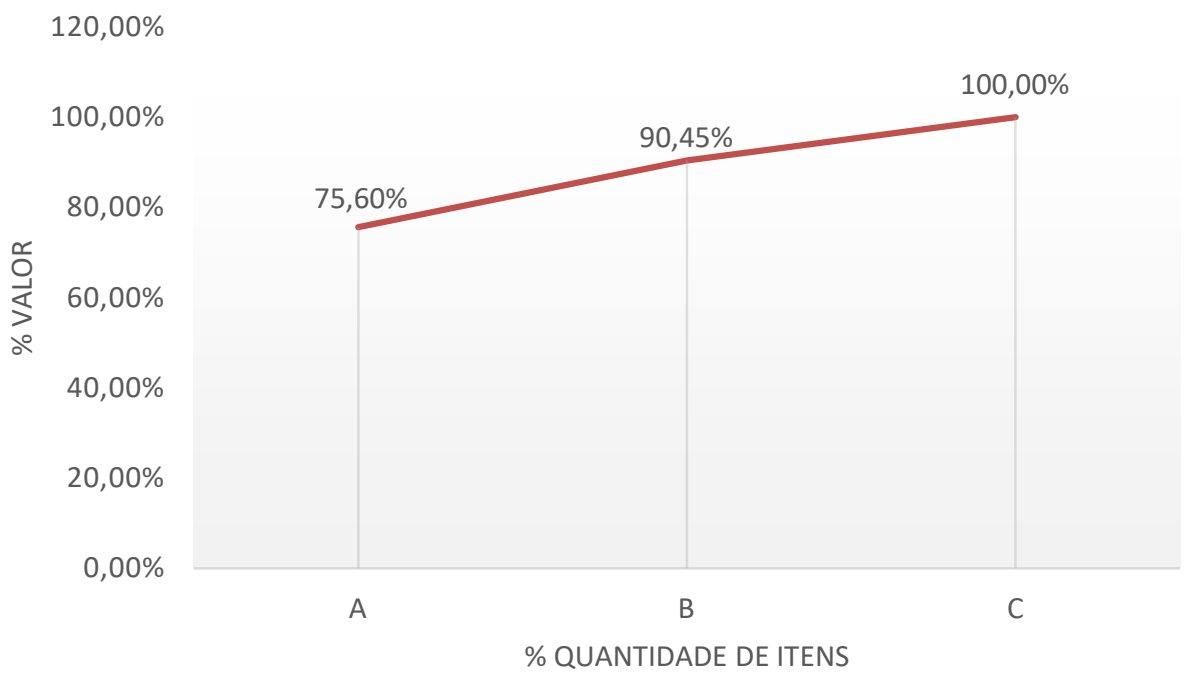

A Tabela 3 contém a lista detalhada dos produtos conforme sua classificação, os produtos não receberam o nome real por fins de confidencialidade. No entanto os valores e receitas foram omitidos para não comprometer informações sigilosas da empresa.

Tabela 3: Classificação ABC dos produtos

\begin{tabular}{|l|c|c|c|c|c|}
\hline \multicolumn{1}{|c|}{ Produto } & Classif. & Qntd. / Kg & \%(Acum.)Vendas & $\begin{array}{c}\text { \%(Acum) } \\
\text { Itens }\end{array}$ & ABC \\
\hline Macarrão Tipo 1 & 1 & 6544510 & $33 \%$ & $1 \%$ & \\
\hline Biscoito Tipo 1 & 2 & 623640 & $38 \%$ & $2 \%$ \\
\hline Biscoito Tipo 2 & 3 & 656512 & $44 \%$ & $3 \%$ \\
\hline Café Tipo 1 & 4 & 234279 & $48 \%$ & $3 \%$ & A \\
\hline Biscoito Tipo 3 & 5 & 386828 & $51 \%$ & $4 \%$ \\
\hline Macarrão Tipo 2 & 6 & 411710 & $53 \%$ & $5 \%$ & $6 \%$ \\
\hline Biscoito Tipo 4 & 7 & 223280 & $56 \%$ & $7 \%$ & \\
\hline Biscoito Tipo 5 & 8 & 205896 & $57 \%$ & \\
\hline
\end{tabular}




\begin{tabular}{|c|c|c|c|c|c|}
\hline Biscoito Tipo 6 & 9 & 198544 & $59 \%$ & $8 \%$ & \\
\hline Macarrão Tipo 2 Especial & 10 & 216264 & $61 \%$ & $9 \%$ & \\
\hline Biscoito Tipo 7 & 11 & 136492,2 & $63 \%$ & $9 \%$ & \\
\hline Macarrão Tipo 3 & 12 & 207864 & $64 \%$ & $10 \%$ & \\
\hline Biscoito Tipo 8 & 13 & 118626,3 & $66 \%$ & $11 \%$ & \\
\hline Macarrão Tipo 4 & 14 & 252090 & $67 \%$ & $12 \%$ & \\
\hline Biscoito Tipo 9 & 15 & 142036 & $68 \%$ & $13 \%$ & \\
\hline Biscoito Tipo 10 & 16 & 86392,8 & $69 \%$ & $14 \%$ & \\
\hline Biscoito Tipo 11 & 17 & 86213,4 & $70 \%$ & $15 \%$ & \\
\hline Biscoito Tipo 12 & 18 & 81034,2 & $71 \%$ & $15 \%$ & \\
\hline Biscoito Tipo 13 & 19 & 80234,7 & $72 \%$ & $16 \%$ & \\
\hline Biscoito Tipo 14 & 20 & 73360 & $73 \%$ & $17 \%$ & \\
\hline Biscoito Tipo 15 & 21 & 61444,5 & $74 \%$ & $18 \%$ & \\
\hline Biscoito Tipo 16 & 22 & 62127 & $75 \%$ & $19 \%$ & \\
\hline Biscoito Tipo 17 & 23 & 73396 & $76 \%$ & $20 \%$ & \\
\hline Salgadinho Tipo 1 & 24 & 23022 & $76 \%$ & $21 \%$ & \multirow{24}{*}{$\mathrm{B}$} \\
\hline Biscoito Tipo 18 & 25 & 66152 & $77 \%$ & $21 \%$ & \\
\hline Macarrão Tipo 5 & 26 & 115070 & $78 \%$ & $22 \%$ & \\
\hline Biscoito Tipo 19 & 27 & 48925,5 & $78 \%$ & $23 \%$ & \\
\hline Biscoito Tipo 20 & 28 & 46749,3 & $79 \%$ & $24 \%$ & \\
\hline Biscoito Tipo 21 & 29 & 60136 & $79 \%$ & $25 \%$ & \\
\hline Mistura para Bolos Tipo 1 & 30 & 56112 & $80 \%$ & $26 \%$ & \\
\hline Biscoito Tipo 22 & 31 & 52880 & $80 \%$ & $26 \%$ & \\
\hline Salgadinho Tipo 2 & 32 & 22863 & $81 \%$ & $27 \%$ & \\
\hline Biscoito Tipo 23 & 33 & 29283,8 & $81 \%$ & $28 \%$ & \\
\hline Salgadinho Tipo 3 & 34 & 21804 & $82 \%$ & $29 \%$ & \\
\hline Biscoito Tipo 24 & 35 & 38126,4 & $82 \%$ & $30 \%$ & \\
\hline Salgadinho Tipo 4 & 36 & 13802,5 & $83 \%$ & $31 \%$ & \\
\hline Biscoito Tipo 25 & 37 & 23073 & $83 \%$ & $32 \%$ & \\
\hline Biscoito Tipo 26 & 38 & 30638,4 & $84 \%$ & $32 \%$ & \\
\hline Biscoito Tipo 27 & 39 & 48112 & $84 \%$ & $33 \%$ & \\
\hline Biscoito Tipo 28 & 40 & 40845 & $84 \%$ & $34 \%$ & \\
\hline Salgadinho Tipo 5 & 41 & 13789,5 & $85 \%$ & $35 \%$ & \\
\hline Biscoito Tipo 29 & 42 & 29671,2 & $85 \%$ & $36 \%$ & \\
\hline Biscoito Tipo 30 & 43 & 28618,2 & $85 \%$ & $37 \%$ & \\
\hline Biscoito Tipo 31 & 44 & 15147 & $86 \%$ & $38 \%$ & \\
\hline Salgadinho Tipo 6 & 45 & 13092,5 & $86 \%$ & $38 \%$ & \\
\hline Biscoito Tipo 32 & 46 & 27970,8 & $87 \%$ & $39 \%$ & \\
\hline Biscoito Tipo 33 & 47 & 44568 & $87 \%$ & $40 \%$ & \\
\hline
\end{tabular}


Sousa, D. C. F.; Claudino, C. N. Q.; Aquino, J. T.; Melo, F. J. C. Revista Gestão.Org, v. 15, n. 2, 2017. p. 546-563

ISSN 1679-1827

http://www.revista.ufpe.br/gestaoorg

\begin{tabular}{|c|c|c|c|c|c|}
\hline Biscoito Tipo 34 & 48 & 19464,2 & $87 \%$ & $41 \%$ & \\
\hline Biscoito Tipo 35 & 49 & 22727,04 & $88 \%$ & $42 \%$ & \\
\hline Biscoito Tipo 36 & 50 & 19545 & $88 \%$ & $43 \%$ & \\
\hline Biscoito Tipo 37 & 51 & 18876 & $88 \%$ & $44 \%$ & \\
\hline Biscoito Tipo 38 & 52 & 26406,9 & $89 \%$ & $44 \%$ & \\
\hline Biscoito Tipo 39 & 53 & 18043,2 & $89 \%$ & $45 \%$ & \\
\hline Biscoito Tipo 40 & 54 & 13167 & $89 \%$ & $46 \%$ & \\
\hline Biscoito Tipo 41 & 55 & 30604 & $90 \%$ & $47 \%$ & \\
\hline Biscoito Tipo 42 & 56 & 20386,8 & $90 \%$ & $48 \%$ & \\
\hline Macarrão Tipo 6 & 57 & 37866 & $90 \%$ & $49 \%$ & \\
\hline Biscoito Tipo 43 & 58 & 5781,6 & $90 \%$ & $50 \%$ & \\
\hline Biscoito Tipo 44 & 59 & 23587,2 & $91 \%$ & $50 \%$ & \multirow{28}{*}{$\mathrm{C}$} \\
\hline Salgadinho Tipo 7 & 60 & 11226 & $91 \%$ & $51 \%$ & \\
\hline Salgadinho Tipo 8 & 61 & 12702 & $91 \%$ & $52 \%$ & \\
\hline Mistura para Bolos Tipo 2 & 62 & 29841,6 & $92 \%$ & $53 \%$ & \\
\hline Biscoito Tipo 45 & 63 & 21348,6 & $92 \%$ & $54 \%$ & \\
\hline Macarrão Tipo 7 & 64 & 54990 & $92 \%$ & $55 \%$ & \\
\hline Biscoito Tipo 46 & 65 & 20521,2 & $92 \%$ & $56 \%$ & \\
\hline Biscoito Tipo 47 & 66 & 5149,8 & $93 \%$ & $56 \%$ & \\
\hline Biscoito Tipo 48 & 67 & 15759 & $93 \%$ & $57 \%$ & \\
\hline Biscoito Tipo 49 & 68 & 20580,3 & $93 \%$ & $58 \%$ & \\
\hline Biscoito Tipo 50 & 69 & 32588 & $94 \%$ & $59 \%$ & \\
\hline Biscoito Tipo 51 & 70 & 19679,4 & $94 \%$ & $60 \%$ & \\
\hline Biscoito Tipo 52 & 71 & 27712 & $94 \%$ & $61 \%$ & \\
\hline Tempero & 72 & 30902 & $94 \%$ & $62 \%$ & \\
\hline Macarrão Tipo 8 & 73 & 28938 & $94 \%$ & $62 \%$ & \\
\hline Biscoito Tipo 53 & 74 & 16917,6 & $95 \%$ & $63 \%$ & \\
\hline Biscoito Tipo 54 & 75 & 12801,6 & $95 \%$ & $64 \%$ & \\
\hline Biscoito Tipo 55 & 76 & 18119,4 & $95 \%$ & $65 \%$ & \\
\hline Macarrão Tipo 9 & 77 & 27960 & $95 \%$ & $66 \%$ & \\
\hline Biscoito Tipo 56 & 78 & 27668 & $96 \%$ & $67 \%$ & \\
\hline Biscoito Tipo 57 & 79 & 14342,16 & $96 \%$ & $68 \%$ & \\
\hline Salgadinho Tipo 9 & 80 & 6511,25 & $96 \%$ & $68 \%$ & \\
\hline Salgadinho Tipo 10 & 81 & 7501,5 & $96 \%$ & $69 \%$ & \\
\hline Biscoito Tipo 58 & 82 & 24416 & $96 \%$ & $70 \%$ & \\
\hline Biscoito Tipo 59 & 83 & 12460,56 & $97 \%$ & $71 \%$ & \\
\hline Café Tipo 2 & 84 & 34653 & $97 \%$ & $72 \%$ & \\
\hline Biscoito Tipo 60 & 85 & 18332 & $97 \%$ & $73 \%$ & \\
\hline Salgadinho Tipo 11 & 86 & 6690 & $97 \%$ & $74 \%$ & \\
\hline
\end{tabular}




\begin{tabular}{|c|c|c|c|c|}
\hline Biscoito Tipo 61 & 87 & 11770,08 & $97 \%$ & $74 \%$ \\
\hline Biscoito Tipo 62 & 88 & 12440,4 & $98 \%$ & $75 \%$ \\
\hline Mistura para Bolos Tipo 3 & 89 & 16848 & $98 \%$ & $76 \%$ \\
\hline Biscoito Tipo 63 & 90 & 12409,8 & $98 \%$ & $77 \%$ \\
\hline Mistura para Bolos Tipo 4 & 91 & 15902,4 & $98 \%$ & $78 \%$ \\
\hline Biscoito Tipo 64 & 92 & 10953,6 & $98 \%$ & $79 \%$ \\
\hline Biscoito Tipo 65 & 93 & 7770 & $98 \%$ & $79 \%$ \\
\hline Salgadinho Tipo 12 & 94 & 5898 & $98 \%$ & $80 \%$ \\
\hline Biscoito Tipo 66 & 95 & 8821,68 & $99 \%$ & $81 \%$ \\
\hline Biscoito Tipo 67 & 96 & 10678,2 & $99 \%$ & $82 \%$ \\
\hline Salgadinho Tipo 13 & 97 & 4180 & $99 \%$ & $83 \%$ \\
\hline Biscoito Tipo 68 & 98 & 7047,6 & $99 \%$ & $84 \%$ \\
\hline Biscoito Tipo 69 & 99 & 8370 & $99 \%$ & $85 \%$ \\
\hline Macarrão Tipo 10 & 100 & 21710 & $99 \%$ & $85 \%$ \\
\hline Biscoito Tipo 70 & 101 & 6045,2 & $99 \%$ & $86 \%$ \\
\hline Salgadinho Tipo 14 & 102 & 4069,5 & $99 \%$ & $87 \%$ \\
\hline Biscoito Tipo 71 & 103 & 5644,8 & $100 \%$ & $88 \%$ \\
\hline Macarrão Tipo 11 & 104 & 6192 & $100 \%$ & $89 \%$ \\
\hline Biscoito Tipo 72 & 105 & 1283,4 & $100 \%$ & $90 \%$ \\
\hline Biscoito Tipo 73 & 106 & 4570,5 & $100 \%$ & $91 \%$ \\
\hline Café Tipo 3 & 107 & 2600 & $100 \%$ & $91 \%$ \\
\hline Salgadinho Tipo 15 & 108 & 1723,8 & $100 \%$ & $92 \%$ \\
\hline Café Tipo 4 & 109 & 2009 & $100 \%$ & $93 \%$ \\
\hline Salgadinho Tipo 16 & 110 & 1324,35 & $100 \%$ & $94 \%$ \\
\hline Macarrão Tipo 12 & 111 & 1562,4 & $100 \%$ & $95 \%$ \\
\hline Biscoito Tipo 74 & 112 & 1671 & $100 \%$ & $96 \%$ \\
\hline Biscoito Tipo 75 & 113 & 410,4 & $100 \%$ & $97 \%$ \\
\hline Café Tipo 5 & 114 & 756 & $100 \%$ & $97 \%$ \\
\hline Café Tipo 6 & 115 & 408 & $100 \%$ & $98 \%$ \\
\hline Biscoito Tipo 76 & 116 & 10,08 & $100 \%$ & $99 \%$ \\
\hline Biscoito Tipo 77 & 117 & 7,2 & $100 \%$ & $100 \%$ \\
\hline
\end{tabular}

\subsection{Layout}

A análise do layout foi realizada em um período de 15 dias para avaliar a real necessidade de alocação de determinados grupos de produtos que ocupavam espaços demasiados e não possuíam a demanda esperada. Também foi considerada a necessidade de proximidade dos produtos nas docas, visto que a empresa trabalha com uma área de picking que alocam os pallets dos principais produtos em proximidade com as docas.

$\mathrm{O}$ atual layout por possibilitar dificuldades na gestão de estoque, propõe-se a implementação de um controle de armazenagem planejado que identifique o local disponível para alocação dos produtos antes que o mesmo seja solicitado, acresce-se a necessidade de identificação de validade e descrição do produto sob aspecto de maior visibilidade, bem como a alocação conforme classificação disponível na lista de pedidos. Essas informações 
devem ser cadastradas na planilha de controle de estoque proposta na Tabela 1.

Objetivando melhoria na eficiência no processo de separação e a redução de custo, a proposta de melhoria de layout prezou em atender os seguintes pontos: distribuição de produtos, prezando pela rotatividade, grupo de produtos e sequência de separação; padronização de endereços; quantidade de docas; e, endereçamento simples e acurado.

Sugere-se uma nova doca para grandes cargas com capacidade de até 28 pallets, para carregamento e descarrego de carretas, reduzindo a quantidade de pessoal necessária envolvida armazenagem dos produtos e viabilizando o estoque de cargas poetizadas previamente programadas. O novo layout proposto com as devidas modificações segue conforme Figura 3.

Figura 3: Proposta de melhoria no layout e posicionamento

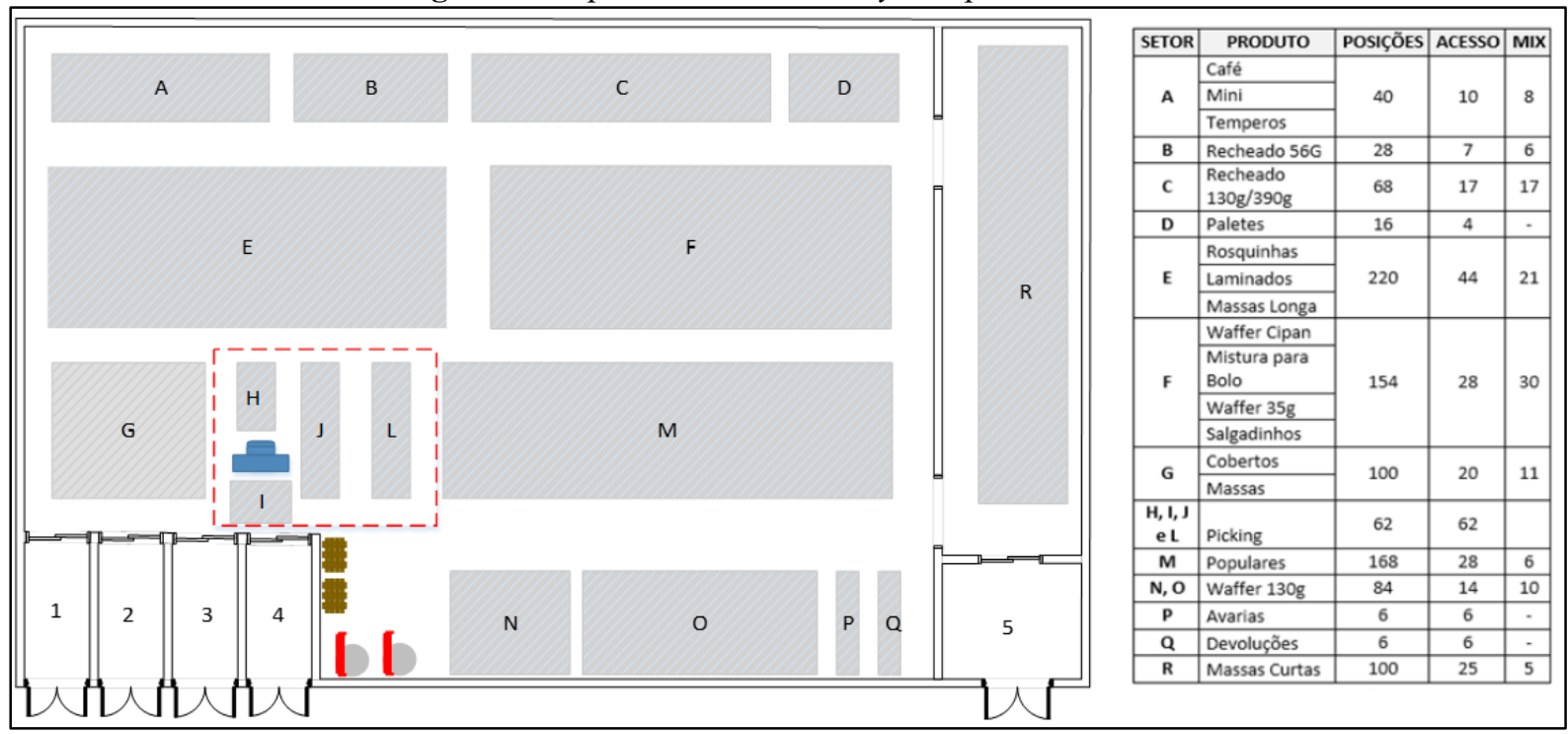

\section{Conclusões}

O presente estudo teve como objetivo analisar a utilização de ferramentas gerenciais para acompanhar os estoques e aumentar a eficiência da empresa, que atua no segmento de produção de bens alimentícios.

Como presumido na literatura (BALLOU, 2004; SOUSA et al., 2017), manter estoques requer alocação de capital de giro. Desta forma, controlar seus níveis de modo a se obter o máximo de resultado deve ser o objetivo de todo gestor. A melhor forma identificada para a empresa estudo de caso é ter uma política de estoque de segurança, dada a ausência de controle devido a dinâmica de mercado, mas possuindo níveis de estoque que amortizem essas variações e viabiliza uma adequada capacidade de atendimento.

A empresa apresentou recorrentes problemas de devoluções de produtos e falta de produtos, que remontam a atual falta de uma política de controle de estoques bem definida e eficiente. Durante as análises foi revelada a ausência de regras claras a respeito dos procedimentos de armazenagem e controle de vencimento dos produtos.

Baseado nessas premissas o presente trabalho obteve êxito em sua proposta de atingir conhecimentos práticos e a melhoria de um setor propiciada pela proposta de aplicação técnicas de controle de estoque fazendo uso de indicadores que proporcionam certa melhoria para a gestão. Em virtude desses resultados e diante da necessidade de se manter estoques, faz-se necessário a utilização de ferramentas de controle dos níveis de estoque para que se possa eliminar ao máximo as incertezas e as compras excessivas ou desnecessárias. Nesse sentindo, esse trabalho propôs uma planilha de controle de estoque que contribui para a manutenção de níveis satisfatórios de atendimento da demanda.

A classificação $\mathrm{ABC}$ foi desenvolvida com o objetivo de identificar os produtos que merecem maior atenção quanto ao controle, visto sua significativa participação nas receitas da empresa. Também foi proposta uma melhoria no layout da empresa considerando o endereçamento de produtos conforme grupos de gênero a fim de aperfeiçoar as atividades dos setores.

A utilização dos indicadores de níveis de estoque contribui para o equilíbrio econômico e financeiro da organização quando da análise dos resultados, provendo um método de gerenciamento direcionado as 
necessidades da empresa. Todavia, é importante mencionar que o modelo proposto de níveis de estoque é considerado confiável segundo os métodos científicos e os resultados coletados na empresa, no entanto, faz-se necessário uma experimentação prática quanto à adequação dos mesmos visto as recorrentes variações no mercado.

Em suma, foi possível perceber que, para uma melhor eficiência da operação do sistema de estoque da empresa, elementos como: gestão, treinamento, estrutura e controle dos estoques devem ser tratados de forma alinhada e interdependente, buscando balizar não só a capacidade interna da empresa, mas a cadeia produtiva na qual ela esta inserida, ratificando as ideias difundidas pela literatura (PALADINI et al., 2015; SLACK et al., 2010; BALLOU, 2004). Nesses termos, o controle de estoque nas empresas deve ser visto de maneira estratégica, integrando-se aos diversos agentes atuantes, pois uma ausência de um controle de estoque adequado pode representar a perda tangíveis e intangíveis para empresa.

\section{Referências}

ANDRIOLI, R. F.; DIEHL, C. A.; HANSEN, P. Proposta de Modelo Flexível para Apoio à Decisão de Externalização: Uma Aplicação em Logística de Transporte. Gestão.Org. v.13, n.2, p. 116-129, 2015.

AQUINO, J. T.; JERONIMO, T. B.; SILVA, V. C. L.; MELO, F. J. C. Uma abordagem multicritério para análise de riscos financeiros em projetos de tecnologia da informação. In: VII Simpósio de Engenharia de Produção do Vale do São Francisco, 2017, Juazeiro - BA.

ARIAS, J. A. C.; RODRIGUEZ, C. M. T.; NOVAES, ANTÔNIO G. N. A Cadeia de Suprimentos para Produtos Inovadores da Indústria Eletônica. Espacios (Caracas), v.37, n.28, p.7-13, 2016.

BALLOU, R. H. Business Logistics: Supply Chain Management. 5th Edition, Pearson, 2004

BARTHOLDI, J. J.; HACKMAN, S. T. Warehouse \& distribution science, The Supply Chain and Logistics Institute, Atlanta, USA, 2010. Disponível em: www.warehouse-science.com. Acesso em: 03 out. de 2015.

BENITO, E.F.; CLAY, C.W. Know Your ABC. Management Decision. v.26, n.3, p.20 - 24, 1988.

BUENO, A.F.; ALENCAR, L. H. The maturity of rail freight logistics service providers in Brazil. Production. v.26, n.2, p.359-372, 2016.

CHIARINI, A.; VAGNONI, E. Strategies for modern operations management: answers from European manufacturing companies. Benchmarking: An International Journal. v.24, n.4, p.1065-1081, 2017.

CRUZ, S. L.; ARAÚJO, M. C. B.; ALENCAR, L. H. Transporte de cabotagem no Porto de Suape, Pernambuco: uma pesquisa exploratória. Production, v.25, n.3 p.560-570, 2015.

GIANESI, I. G. N. Implementing manufacturing strategy through strategic production planning. International Journal of Operations \& Production Management, v. 18, n.3, p.286-299, 1998.

GIANESI, I. G. N.; BIAZZI, J. L. Strategic management of stocks. Revista de Administração. v. 46, n.3, p.290304, 2011.

Kaminski, M. T.; de Oliveira, J. H. R.; Ribeiro, R. P; de Oliveira, R. M.; Siluk, M. H. P. Um estudo da viabilidade de implementação do just in time na Santa Fé Vagões S/A. XXX Encontro Nacional de Engenharia de Produção, São Paulo, pp- 1-13, 2010.

KAMPF, R.; LORINCOVÁ, S. The Application of ABC Analysis to Inventories in the Automatic Industry Utilizing the Cost Saving Effect Primjena ABC analize za inventar u automatiziranoj proizvodnji koristeći učinak uštede troškova. International Journal of Maritime Science \& Technology, v. 63, n. 3, p. 120-125, 2016.

LUDWIG, J. P.; FAIZ, E. B.; SCHEIFLER, T.; DREGER, A. A.. The application of the just in time methodology for the reduction of inventories in an industry of the furniture industry. Journal of Lean Systems, v.1, n.2, pp. 25-39, 2016.

MELO, F. J. C.; AQUINO, J. T. Os 5S como diferencial competitivo para o sistema de gestão da qualidade: estudo de caso de uma empresa de aços longos. Gestão.Org. v. 13, n.2, p. 176-186, 2015.

MilANi, A. A.; GASPAR, V.; AlBRECHT, A. J. P.; FAUSTO, D. A.; MiGLiAVACCA, R. A. Processo de gestão da carteira de clientes. Revista iPecege, v. 1, n.2, p. 168, 2015.

MINNER, S.; TRANSCHEL, S. Periodic review inventory-control for perishable products under service-level 
constraints. OR Spectrum, v.32, n.4, p. 979-996, 2010.

NALLUSAMY, S; BALAJI, R; SUNDAR, S. Proposed Model for Inventory Review Policy through ABC Analysis in an Automotive Manufacturing Industry. International Journal of Engineering Research in Africa, v. 29, p. 165-174, 2017.

NEMTAJELA, N; MBOHWA, C. Inventory Management Models and Their Effects on Uncertain Demand. IEEE International Conference on Industrial Engineering and Engineering Management (IEEM), Bali, pp. 1046-1049, 2016.

PALADINI, E. P.; NOGAS, C. Strategic accounting as a competitiveness factor of globalized marketing companies. Asian Journal of Business and Management, v.1, n.3 p.115-125, 2013.

PALADINI, E. P.; AVILÉS, B. G.; BROCHE, G. R.; GÓMEZ, A. C. Development and Application of a Model to Minimize Variability in a Vegetable Pulp Productive Process. Journal of Food Process Engineering. v.38, n.6, p.517-526, 2015.

PASQUALI, F. D. O Sistema Just-in-Time (JIT) Um Estudo De Caso: Produção Em Série De Móveis De Madeira. Trabalho de Conclusão de Curso (Ciências Contábeis ). Universidade Federal de Santa Catarina. UFSC. Florianopolis, SC, 2010.

Pierskalla W. P., Roach C.D. Optimal issuing policies for perishable inventory. Management Science, v.18, n.11, pp. 603-614, 1975.

POZO, H; AKABANE, G. K.; GALHARDI, A. C.; PETEROSSI, H. Sustainability As A Success Factor In Global Operations: A Survey Of Car Manufacturing Supply Chains. Independent Journal of Management \& Production, v.6, n.2, p.525-547, 2015.

ROGERS, P.; RIBEIRO, K. C. S.; ROGERS, D. Avaliando o Risco na Gestão Financeira de Estoques.. In: VII Simpósio de Administração da Produção, Logística e Operações Internacionais - SIMPOI, 2004, São Paulo. RUDIO, F.V. Introdução ao Projeto de pesquisa cientifica. 43 edição, Vozes, 2015.

RUFINO, P. E.; ANDRADE JÚNIOR, P.P. Indicadores de qualidade com base em um sistema de custos da qualidade: um estudo de caso. Qualitas, v.15, n.1, p.1-18, 2014.

SANTOS, V. N.; SILVA, T. B. J.; LAY, L. A.; SANTOS, L. N.; VALERETTO, G. J. Estratégias organizacionais e o desempenho das empresas que realizaram initial public offering (IPO). Gestão.Org. v.15, n.1, p. 46-60, 2017.

SANTOS R. R.; MELO, F. J. C.; CLAUDINO, C. N. Q.; MEDEIROS, D. D. Model for formulating competitive strategy: the supplementary health sector case. Benchmarking: An International Journal. v.24,n.1, p. 219-243, 2017.

SILVEIRA, A. O.; COUTINHO, H. H. Trabalho padronizado: a busca por eliminação de desperdícios. Revista Inicia, v.8, n.1, p. 8-16, 2008.

SINGH, J.; SINGH, H. Continuous improvement philosophy - literature review and directions. Benchmarking: An International Journal. v.22, n.1, p.75 - 119, 2015.

SLACK, N.; CHAMBERS, S.; JOHNSTON, R. Operations Management. Sixth Ed.: Prentice Hall, 2010.

SOUZA, A. J. S.; BENTO, C. A.; MARTINS, R. Z.; LOPES, E. S.; GALVÃO, H. M. Análise da administração do capital de giro em uma empresa localizada na cidade de Guaratinguetá. Revista de Administração da Fatea. v.3, n.3, p.102-107, 2010.

SOUSA, D. C. F.; CLAUDINO, C. N. Q.; MELO, F. J. C. Aplicação da gestão da qualidade para melhoria da eficiência produtiva e de longo prazo em uma indústria de reciclagem. Exacta. v.14, n.4, p.661-676, 2016.

SOUSA, J. V.; JERÔNIMO, T. B.; MELO, F. J. C.; AQUINO, J. T.. Uso do AHP para identificação de perdas da qualidade em empresas de manufatura: um estudo de caso. Exacta. v.15, n.1, p. 89-100, 2017.

SPERANZA, M. Trends in transportation and logistics. European Journal of Operational Research. v.264, n.3, p. 830-836, 2016.

STANLEY, E.; FAWCETT G.K.; RHOADS P.B. People as the bridge to competitiveness. Benchmarking: An International Journal. v.11, n.4, pp. 346 - 360, 2004.

VAN DEN BERG, J.P.; ZIJM, W.H.M. Models for warehouse management: classification and examples. International Journal of Production Economics. v.59, n.1-3, p.519-528,1999.

VOSS, C. A. In: VOSS, C. A. (Org.). Just in time manufacture; IFS, Springer Verlag, 1987. 